\title{
KAJIAN EKOLOGI SASTRA BERBASIS NILAI KEARIFAN LOKAL DALAM CERPEN "ORANG BUNIAN" KARYA GUS TF SAKAI
}

\author{
Nur Ahmad Salman Herbowo \\ Universitas Andalas Padang, Indonesia \\ Email: salman.herbowo@gmail.com
}

\begin{abstract}
This research discusses the short story "Orang Bunian" by Gus TF Sakai as a material object and ecological studies related to local wisdom and myths in literary works as formal objects. The theory that used is ecocriticism. The method used is descriptive qualitative research analysis. The short story "Orang Bunian" is one of the short stories of Gus TF Sakai in the short story anthology of Kaki Yang Terhormat that contains narratives about myths and people who believe in them and relating to nature and the environment. This is research is to identificating and analizing the short story based on the ecology approach and what its relation with local wisdom. The result of analysis showed that this myth is the part of local wisdom of that area. The society's believe on orang bunian indirectly affected them in their behavior on maintain and conserving the natural source around them. Besides the presents of orang bunian also affected in the development of culture and knowledge, the believed in orang bunian give the people the understanding about a proper time for hunting in the forest. so it makes orang bunian as the believe and forbidden thing in the society of that short story
\end{abstract}

Keywords: ecology of literature; orang bunian; local wisdom

\begin{abstract}
Abstrak: Penelitian ini menjadikan cerpen "Orang Bunian” karya Gus TF Sakai sebagai objek material dan kajian ekologis yang berhubungan dengan kearifan lokal terkait dengan mitos dalam karya sastra sebagai objek formal. Teori yang digunakan adalah ekokritik. Metode penelitian yang digunakan adalah metode penelitian analisis kualitatif deskriptif. Cerpen "Orang Bunian" merupakan salah satu cerpen Gus TF Sakai dalam kumpulan cerpen Kaki Yang Terhormat yang memuat narasi tentang mitos dan masyarakat yang memercayai berkaitan dengan alam dan lingkungan. Penelitian ini dilakukan dengan tujuan untuk mengidentifikasi serta menganalisis berdasarkan kajian ekologi sastra dalam cerpen tersebut dan hubungannya dengan kearifan lokal di daerah setempat. Hasil penelitian menunjukkan bahwa kehadiran mitos urang bunian merupakan bentuk dari kearifan lokal masyarakat setempat. Kepercayaan masyarakat terhadap kehadiran urang bunian secara tidak langsung berdampak terhadap perliku masyarakat dalam menjaga dan melestarikan sumber daya alam. Selain itu, keberadaan urang bunian juga berdampak terhadap pengembangan kebudayaan dan ilmu pengetahuan, yaitu keberadaanya memberikan pemahaman akan waktu-waktu tertentu yang diperbolehkan untuk berburu di dalam hutan. Sehingga urang bunian dianggap sebagai petuah, kepercayaan dan pantangan bagi masyarakat dalam cerpen tersebut.
\end{abstract}

Kata Kunci: ekologi sastra; orang bunian; kearifan lokal

Permalink/DOI: http://dx.doi.org/10.15408/dialektika.v7i1.13887 


\section{Pendahuluan}

Melestarikan nilai kearifan lokal merupakan salah satu cara dalam menjaga budaya tradisional di Indonesia. Sebagai negara yang multikultural dan multietnik, masyarakat Indonesia mempunyai tradisi dan tata cara tersendiri dalam berinteraksi dengan alam. Sebuah tradisi yang sarat nilai luhur dalam memperlakukan alam dengan membaca dan memaknai tanda-tanda yang diberikannya. Kemajemukan suku yang ada di Indonesia menjadikannya sebagai bangsa yang menyimpan keberagaman bentuk tradisi dalam menjaga alam dan lingkungan. Tidak jarang, bentuk kearifan lokal masyarakat itu melatarbelakangi penciptaan karya beberapa penulis sastra di Indonesia. Dalam berbagai genre karya sastra tidak jarang ditemukan bentuk kearifan lokal sebagai tema ceritanya.

Kearifan lokal adalah tata nilai atau perilaku hidup masyarakat lokal dalam berinteraksi dengan lingkungan tempatnya hidup secara arif. ${ }^{1}$ Beberapa bentuk kearifan lokal yang dituliskan dalam karya sastra berkaitan dengan mitos dan kondisi alam, seperti hutan dan berbagai isinya yang saling berkaitan dengan kehidupan manusia. Hal itu memberikan informasi kepada pembaca tentang bentuk kearifan lokal suatu kelompok masyarakat. Tentu saja karya sastra yang mengangkat tema semacam itu menarik untuk dibaca. Cerpen "Orang Bunian" karya Gus TF Sakai merupakan salah satu cerpen yang mengangkat tema tentang mitos dan kearifan lokal suatu kelompok masyarakat. Cerpen "Orang Bunian” termuat dalam buku kumpulan cerpen Kaki Yang Terhormat. Cerpen itu sebelumnya pernah dimuat di harian Kompas pada 25 April 2010. ${ }^{2}$

"Orang Bunian" bercerita tentang kenangan seorang ayah pada masa mudanya ketika berburu babi di salah satu bukit di kampung, tepatnya di daerah bukit Burai. Kisah ini mengenai tokoh yang tidak mengindahkan pantangan dan larangan dalam berburu. Padahal mereka mempunyai tradisi tersendiri dalam menghormati alam sebelum kegiatan berburu. Cerita itu bermula dari pertanyaan anak perempuannya mengenai keberadaan orang bunian pada saat ini. Si tokoh Ayah menjawabnya dengan menceritakan peritiwa aneh ketika sedang berburu babi, peristiwa yang dapat disebut sudah di luar nalar manusia, persitiwa yang sudah masuk dalam dunia gaib, sebuah peristiwa yang sulit untuk dilupakan. Sebuah kisah memadukan mitos yang hidup di tengah masyarakat dengan bentuk kearifan lokal masyarakatnya dalam berinteraksi dan menjaga lingkungan.

${ }^{1}$ Supriatna dalam Sudikan, Ekologi Sastra, (Lamongan: Pustaka Ilalang Grup, 2016) h.77.

${ }^{2}$ Gus TF Sakai, Kaki Yang Terhormat, (Jakarta: Gramedia Pustaka Utama, 2012) h.116. 
Penelitian ini mengambil objek material salah satu cerpen yang termuat dalam kumpulan cerpen Kaki Yang Terhormat karya Gus TF Sakai, yaitu cerpen "Orang Bunian". Berdasarkan pandangan latar belakang yang telah dituliskan sebelumnya, objek formil dari penelitian ini adalah kajian ekokritik terhadap cerpen tersebut. Peneliti bermaksud meneliti bagaimana bentuk kearifan lokal masyarakat dalam mejaga alamnya dari tradisi berburu babi. Dengan begitu, penelitian ini diharapkan mampu mengetahui bentuk-bentuk kearifan lokal masyarakat dalam teks "Orang Bunian" (masyarakat adat Minangkabau) dari tradisi berburu babi. Sehingga dapat memberikan pemahaman betapa pentingnya mengetahui nilai-nilai kearifan lokal nenek moyang dalam berintekrasi dengan alam sebagai sebuah warisan budaya.

Persoalan lingkungan, alam dan bentuk-bentuk kearifan lokal menjadi salah satu pendekatan dalam menganalisis karya sastra. Kajian yang memperhatikan hubungan antara makhluk hidup dengan lingkungannya (alam) merupakan bentuk kajian sastra dengan pendekatan ekologi. Ekologi ialah ilmu yang mempelajari hubungan timbal balik antara makhluk hidup dengan lingkungannya. ${ }^{3}$ Atas dasar defenisi tersebut dapat dikemukakan bahwa ekologi sastra juga mencari hubungan timbal balik antara sastra dengan lingkungannya. Hubungan resiprokal itu penting untuk melihat keterkaitan satu sama lain.

Dalam cerpen "Orang Bunian” banyak diksi simbol-simbol alam yang digunakan sebagai latar cerita. Misalnya ada diksi lembah, lakuak, hutan, dan bukit yang digambarkan sebagai latar cerita. Selain dari itu, nama binatang seperti babi dan anjing, kemudian diksi batu, rotan, pepohonan, dedaunan, akar, dan kabut juga menjadi pilihan kata dalam menuliskan cerpen ini. Dengan mengangkat tata cara berburu babi dengan segala bentuk ritual dan aturan tradisionalnya, menguatkan interpretasi pembaca bahwa cerpen ini merupakan teks yang mengangkat persoalan alam dan lingkungan dengan nilai-nilai kearifan lokal pada suatu kelompok masyarakat. Menggunakan pendekatan kajian ekologi sastra yang berfokus terhadap ecocriticism kearifan lokal lingkungan (ekologis) dalam teks sastra, merupakan cara analisis yang tepat dalam mengkaji cerpen ini.

Kajian ekologi sastra berupaya untuk menemukan spesifikasi lebih tepat mengenai hubungan antara kegiatan manusia dan proses alam tertentu dalam suatu kerangka analisis ekosistem atau menekankan saling ketergantungan

3 Suwardi Endraswara, Metodologi Penelitian Ekologi Sastra: Konsep, Langkah, dan Penerapan, (Yogyakarta: CAPS, 2016) h.3. 
sebagai suatu komunitas alam. ${ }^{4}$ Pendapat lain yang menguatkan argumen sebelumnya adalah penjabaran mengenai jenis kritik ekologi dalam sastra Indonesia, setidaknya ada lima jenis yaitu genre sastra ekologis, kearifan lokal lingkungan (ekologis) dalam karya sastra, metafora (alam) dalam karya sastra, kategori ekokritik baru; kelas, gender, dan ras, serta kritik lingkungan dalam sastra kontemporer dan sastra populer.

Penjelasan lebih rinci mengenai persamaan ekokritik sastra dan ekologi sastra, yaitu (1) keduanya selalu terfokus pada sastra sebagai bahan kajian, (2) keduanya memperhatikan ihwal lingkungan. Perbedaan ekokritik sastra dan ekologi sastra, yaitu terletak pada aspek kajiannya. ${ }^{6}$ Jika ekokritik menekankan pada aspek kritik, ekologi sastra tidak selalu pada kritik. Dalam pembahasan ekologis dalam karya sastra juga dapat mempertimbangkan bentuk-bentuk kearifan lokal. Adapun pengertian kearifan adalah nilai-nilai luhur yang berlaku dalam tata kehidupan masyarakat untuk antara lain mengelola lingkungan hidup secara lestari.

Defenisi lain mengenai kearifan lokal merupakan semua bentuk pengetahuan, keyakinan, pemahaman atau wawasan serta adat kebiasaan atau etika yang menuntun perilaku manusia dalam kehidupan di dalam komunitas ekologis. ${ }^{8}$ Bentuk-bentuk kearifan lokal yang ada dalam masyarakat dapat berupa nilai, norma, kepercayaan, dan aturan-aturan khusus. Bentuk yang bermacam-macam itu mengakibatkan fungsi kearifan lokal menjadi banyak pula. Fungsi kearifan lokal, diantaranya: 1) sebagai konservasi dan pelestarian sumber daya alam; 2) untuk mengembangkan sumber daya manusia; 3) sebagai pengembangan kebudayaan dan ilmu pengetahuan; dan 4) sebagai petuah, kepercayaan, sastra, dan pantangan. ${ }^{9}$

Kearifan lokal merupakan modal utama masyarakat dalam membangun dirinya tanpa merusak tatanan sosial yang adaptif dengan lingkungan alam sekitarnya. Kearifan lokal dibangun dari nilai-nilai sosial yang dijunjung dalam struktur sosial masyarakat sendiri dan memiliki fungsi sebagai pedoman,

\footnotetext{
${ }^{4}$ Suwardi Endraswara, Metodologi Penelitian ekologi..., h. 18.

${ }^{5}$ Sudikan, Ekologi Sastra, (Lamongan: Pustaka Ilalang Grup, 2016) h. xvii.

${ }^{6}$ Suwardi Endraswara, Ekokritik Sastra: Konsep, Teori, dan Terapan, (Yogyakarta: Morfolingua, 2016) h.5.

${ }^{7}$ Anonim. 2009. Undang-Undang Republik Indonesia Nomor 32 Tahun 2009 Tentang Perlindungan dan Pengelolaan Lingkungan Hidup. Dalam laman Kementerian Koordinator Pembangunan Manusia dan Kebudayaan https://www.kemenkopmk.go.id/content/uu-nomor-32-tahun-2014 Diunduh pada 12 Desember 2019 pukul 13:15 WIB.

${ }^{8}$ Sudikan, Ekologi Sastra, (Lamongan: Pustaka Ilalang Grup, 2016) h.77.

${ }^{9}$ Sudikan, Ekologi Sastra...., h.78.
} 
pengontrol, dan rambu-rambu untuk berperilaku dalam berbagai dimensi kehidupan baik saat berhubungan dengan sesama maupun dengan alam. ${ }^{10}$ Dalam menganalisis cerpen ini digunakan pendakatan secara ekologi dengan melihat kearifan lokal mengenai tradisi suatu kelompok masyarakat dalam membaca tanda alam sebelum berburu babi.

Beberapa penelitian yang melakukan kritik kumpulan cerpen Gus TF Sakai yaitu yang dilakukan Miftahul Usman dengan judul "Pergeseran Nilai Budaya Minangkabau dalam Kumpulan Cerpen Kaki Yang Terhormat karya Gus Tf Sakai". ${ }^{11}$ Penelitian ini mengambil dua cerpen yang termuat dalam ontologi itu, yakni "Kaki Yang Terhormat" dan "Orang Bunian”. Ia melihat terjadinya pergeseran nilai-nilai budaya yang dianut oleh masyarakat adat Minangkabau dalam dua cerpen itu. Hal itu disebabkan oleh kemajuan teknologi yang mengakibatkan terjadinya pergesekan antara tradisi dan modernitas, sehingga mempengaruhi pola pikir masyarakat.

Penelian selanjutnya yaitu yang dilakukan oleh Karami dkk. dengan judul "Masyarakat Minangkabau dalam Kumpulan Cerpen Kaki Yang Terhormat Karya Gus Tf Sakai”. ${ }^{12}$ Ia memaknai realitas sosial yang tersirat dalam kumpulan cerpen tersebut. Ia menyimpulkan bahwa terdapat tujuh realitas sosial masyarakat Minangkabau yang tercermin dalam teks yaitu (1) bahasa, terdapat bahasa Minang dan bahasa Indonesia; (2) sistem ilmu pengetahuan, mengenai alam takambang jadi guru; (3) sistem kemasyarakatan/sistem sosial, berupa tradisi yang menjadi identitas bagi masyarakat Minangkabau; peralatan/perlengkapan, mengenai peralatan/ciri khas bagi masyarakat Minangkabau yang menjadi kebutuhan untuk hidup maupun kebudayaan dari masyarakat Minangkabau; (5) sistem mata pencaharian, mengenai pekerjaan bagi masyarakat Minangkabau (6) kesenian, mengenai seni gerak yang dimiliki masyarakat Minangkabau yaitu silek, dan (7) sistem religi, mengenai budaya ke surau bagi remaja di Minangkabau.

Kemudian beberapa penelitian yang berkaitan dengan objek formal yaitu kajian dengan pendekatan ekologi sastra, yaitu yang dilakukan Chandra dengan

\footnotetext{
${ }^{10}$ Sudikan, Ekologi Sastra..., h. 78 .

${ }^{11}$ Miftahul Usman, "Pergeseran Nilai Budaya Minangkabau dalam Kumpulan Cerpen Kaki Yang Terhormat karya Gus Tf Sakai,” Skripsi Jurusan Sastra Indonesia Fakultas Ilmu Budaya Universitas Andalas, 2019.

12 Habibullah Karami, Wahyudi Rahmat, Aruna Laila, ““'Masyarakat Minangkabau dalam Kumpulan Cerpen Kaki Yang Terhormat Karya Gus Tf Sakai,” Jurnal Bahasa, Vol. 1 No. 2.
} 
judul "Ekokritik dalam Cerpen Indonesia Mutakhir". ${ }^{13}$ Penelitiannya mengulas pelbagai cerpen mutakhir seperti karya S. Prasetyo "Petunjuk Hari Ketujuh", Adi Zamzam "Rob", Tjak S. Parlan "Pergi Ke Bukit", dan Muliadi GF "Alfatiah untuk Pohon-pohon". Ia memaknai hubungan timbal balik teks karya-karya itu dengan lingkungan hidup, termasuk hubungan dengan realitas sosial budaya dan fisik, yang biasanya menjadi perhatian dalam ekologi. Penelitian lain yaitu dilakukan oleh Widianti dengan judul "Kajian Ekologi Sastra dalam Kumpulan Cerpen Kompas 2014 Di Tubuh Tarra Dalam Rahim Pohon". "Ia melakukan ekokritik terhadap beberapa cerpen yang termuat dalam kumpulan cerpen itu. Ia mengungkapkan dalam teks-teks cerpen itu adanya hubungan karya sastra dalam upaya pelestarian alam dan sumber kehidupan, serta kaitannya dengan kepercayaan/mitos.

\section{Metode}

Penelitian ini menggunakan pendekatan ekokritik dengan metode analisis deskriptif. Metode penelitian analisis deskriptif yaitu data yang dikumpulkan adalah berupa kata-kata, sehingga laporan penelitian akan berisi kutipan-kutipan data untuk memberi gambaran penyajiaan laporan tersebut. ${ }^{15}$ Analisis dekrpitif dilakukan dengan mendiskiprikan teks-teks dalam cerpen "Orang Bunian" yang berkaitan dengan nilai-nilai keraifan lokal dan mitos masyarakat adat Minangkabau dalam menjaga alam lingkungannya. Metode tersebut digunakan untuk memaknai secara mendalam fenomena yang berkaitan dengan subjek penelitian. Objek material penelitian ini cerpen "Orang Bunia" karya Gus TF Sakai dalam kumpulan cerpen Kaki Yang Terhormat, sedangkan kajian ekologis yang berhubungan dengan kearifan lokal terkait dengan mitos dalam karya sastra sebagai objek formal.

Sumber data dalam penelitian sastra adalah karya sastra tersebut. ${ }^{16}$ Penelitian ini mengambil sumber datanya adalah cerpen "Orang Bunian" karya Gus TF Sakai dalam kumpulan cerpen Kaki Yang Terhormat. Sedangkan data yaitu "bahan penelitian" atau lebih tepatnya "bahan jadi penelitian" yang

\footnotetext{
Vol. 3 No. 2 .

${ }^{13}$ Afry Adi Chandra, "Ekokritik Dalam Cerpen Indonesia Mutakhir," Jurnal Pena Indonesia (JPI),

${ }^{14}$ Ande Wina Widianti, "Kajian Ekologi Sastra Dalam Kumpulan Cerpen Kompas 2014 Di Tubuh Tarra Dalam Rahim Pohon,” Jurnal Diksatrasia, Vol. 1 No. 2.

${ }^{15}$ Lexy J Moleong, Metodologi Penelitian Kualitatif, (Bandung: Remaja Rosdakarya, 2014) h.11.

16 Sangidu, Penelitian Sastra: Pendekatan, Teori, Metode, Teknik, dan Kiat, (Yogyakarta: Unit Penerbitan Sastra Asia Barat Fakultas Ilmu Budaya Universitas Gadjah mada, 2004) h. 63.
} 
terdapat dalam karya-karya sastra yang akan diteliti. ${ }^{17}$ Adapun data yang digunakan adalah teks-teks termuat dalam cerpen yang berkaitan dengan nilainilai keraifan lokal masyarakat adat Minangkabau dalam menjaga alam lingkunnya pada tradisi berburu babi. Teknik pengumpulan data yang dilakukan dalam penelitian ini menggunakan teknik dokumentasi. Teknik dokumentasi, yaitu mencari data mengenai hal-hal atau variabel yang berupa catatan, transkrip, buku, surat kabar, majalah, notulen rapat, legger, agenda, dan sebagainya. ${ }^{18}$

\section{Pembahasan}

Dalam budaya Minangkabau ada beragam versi cerita mengenai mitos urang bunian. Urang bunian merupakan salah satu cerita mistis yang sudah melegenda di Minangkabau. Namun yang menjadi keseragaman ialah urang bunian adalah makhluk yang memiliki alam tersendiri di berbagai tempat, biasanya di hutan, perbukitan, dan tempat-tempat yang jarang dijamah manusia. ${ }^{19}$ Dalam cerpen "Orang Bunian" disebutkan bahwa dunia orang bunian adalah alam jihin. ${ }^{20}$ Berikut kutipan teksnya:

"Di tengah gelap ceruk, kelam lembah atau lindap lakuak, bisa saja tiba-tiba terbentang dunia terang. Dunia yang semua daun adalah bunga dan semua bunga adalah cahaya. Pohon-pohon meliuk, reranting berjalin, membentuk kubah dan pilar-pilar. Di situlah singgasana, alam jihin dan lelembut, dunia orang bunian. Tapi saat bertemu orang bunian, mereka tak boleh menyebut apa-apa. Karena jika bicara, siapa pun akan terbawa, tertawan, hidup selamanya di dunia orang bunian".

Bahwa tempat orang bunian merupakan daerah-daerah yang memang sepi dan tidak didiami oleh manusia. Dalam dunia orang bunian, semua bisa saja berubah dengan cepat. Dalam teks dituliskan bahwa masyarakat juga mempunyai pantangan tertentu yang tidak boleh dilakukan. Pantangan itu

\footnotetext{
${ }^{17}$ Sangidu, Penelitian Sastra: Pendekatan...., 61.

${ }_{18}$ Arikunto dalam Mardiana Sari, "Ekologi Sastra Pada Puisi Dalam Novel Bapangku Bapunkku Karya Pago Hardian,” Jurnal Parataksis, Vol. 1 No. 1. Hlm. 6.

${ }^{19}$ Wasana, "Mitos dan Legenda Minangkabau di Kenagarian Abai Kecamatan Sangir Batang Hari Kabupaten Solok Selatan”. Laporan Penelitian Dosen Fakultas Ilmu Budaya Universitas Andalas. http://repo.unand.ac.id/9263/1/LaporanPenelitian.pdf. Diunduh pada tanggal 12 Desember 2019 Pukul 16:23 WIB.

${ }^{20}$ Bahasa Minangkabau dalam penyebutan jin. Sedangkan jin dalam KBBI onlie adalah mahkluk halus yang diciptakan dari api.

${ }^{21}$ Gus TF Sakai, Kaki Yang Terhormat, (Jakarta: Gramedia Pustaka Utama, 2012) h. 82.
} 
harus mereka lakukan agar terhindar dari gangguan orang bunian. Namun begitu, hal utama yang dilihat dalam tulisan ini adalah kearifan lokal masyarakat setempat dan simbol-simbol alam yang digunakan dalam menceritakan orang bunian. Dalam menganalisis cerpen ini secara ekologi dengan melihat kearifan lokal adalah mengenai pemahaman masyarakat mengenai dunia lain, tempat tinggal urang bunian.

Gus TF Sakai di dalam teks menuliskan mengenai dunia yang dibelah menjadi dua bagian. Ada lapis atas dan lapis bawah. Lebih lanjut, ia menjelaskan bahwa dunia lapis atas merupakan dunia di balik kabut, dunia yang sangat misterius dan rahasia. Dunia lapis atas dapat dimaknai dunia gaib atau dunia di atas langit. Sedangkan dunia lapis bawah adalah dunia yang biasa ditempati oleh manusia dalam menjalani kehidupan keseharian dan juga oleh sosok gaib. Berikut kutipan teks yang menjabarkan mengenai dunia lapis atas dan bawah tersebut:

"Lalu dunia bagai dibelah. Lapis atas dan lapis bawah. Lapis atas, dunia di balik kabut itu, semata rahasia, kesenyapan, tempat yang entah kenapa dalam kepalanya hanya terhampar malam dan bintang-bintang. Sementara lapis bawah, ia lihat dirinya dan teman-temannya, para pemburu, bersama anjing-anjing yang menghambur dan menyalak, berlarian mengejar babi hutan yang mendudu, melanda semak atau belukar atau apa pun, terhosoh-hosoh ketakutan". ${ }^{22}$

Namun begitu, ada hal menarik mengenai dunia lapis bawah itu. Pada bagian dunia lapis bawah ada dunia lain yang tidak terjamah atau tempattempat sunyi yang ditakuti oleh manusia. Dunia lapis bawah yang secara geografis sulit atau mustahil untuk didiami oleh manusia, dalam teks disebut dengan lembah dan lakuak (bahasa Minangkabau yang menyebut lembahlembah kecil di antara gundukan bukit). Tempat itu menjadi tempat bersemayamnya orang bunian atau disebut juga dalam kepercayaan masyarakat Minangkabau sebagai alam jihin. Berikut kutipan teksnya:

"Tapi, sebetulnya, dunia lapis bawah itu juga tak semata terang. Ada banyak ceruk, lembah, dan lakuak (bahasa mereka untuk menyebut lembah-lembah kecil di antara undukan bukit) yang bila ditempuh akan menangkup lebat dedaun dan akar, menghalangi rembes rambat cahaya, menjadikan mata mereka seolah buta, tak bisa mengenali atau melihat apa-apa, menyerahkan arah hanya pada naluri atau krosak langkah dan gerung salak anjing-anjing mereka. Dan, sebetulnya pula, di lapis bawah ini, bukannya tak ada apa yang ia sebut rahasia”.

${ }^{22}$ Gus TF Sakai, Kaki Yang...., h. 81 . 
"Di tengah gelap ceruk, kelam lembah atau lindap lakuak, bisa saja tiba-tiba terbentang dunia terang. Dunia yang semua daun adalah bunga dan semua bunga adalah cahaya. Pohon-pohon meliuk, reranting berjalin, membentuk kubah dan pilar-pilar. Di situlah singgasana, alam jihin dan lelembut, dunia orang bunian. Tapi saat bertemu orang bunian, mereka tak boleh menyebut apa-apa. Karena jika bicara, siapa pun akan terbawa, tertawan, hidup selamanya di dunia orang bunian". ${ }^{23}$

Bahwa masyarakat dalam cerpen mempunyai kearifan tersendiri dalam membagi alam. Seperti yang dijelaskan sebelumnya, bahwa kearifan lokal yang ada dalam masyarakat dapat berupa nilai, norma, kepercayaan, dan aturanaturan khusus. Bentuk yang bermacam-macam itu mengakibatkan fungsi kearifan lokal menjadi banyak pula dan fungsi yang tepat dari penjabaran teks mengenai dunia urang bunian adalah sebagai petuah, kepercayaan, sastra, dan pantangan. Cerita urang bunian dalam masyarakat Minangkabau selalu dikisahan secara turun temurun. Urang bunian sangat melegenda dalam kehidupan masyarakat Minangkabau, terutama yang tinggal di daerah darek, yaitu daerah asli Minangkabau, yakni Luhak Nan Tigo, Luhak Tanah Datar, Luak Agam, dan Luhak Lima Puluh Kota. ${ }^{24}$ Sehingga masyarakat daerah darek jarang yang tidak mengetahui cerita legenda urang bunian. Bukan sekadar cerita legenda saja, urang bunian juga dipercaya ada dan hadir dalam kehidupan mereka dan tinggal di hutan-hutan yang lebat dan lembab.

Pondasi utama Gus TF Sakai dalam mengembangkan cerpen "Orang Bunian" adalah mengenai larangan dan pantangan tentang gangguan orang bunian yang dipercayai oleh masyarakat Minangkabau. Sebagai sebuah legenda yang sudah turun temurun dipercayai oleh masyarakat Minangkabau, orang bunian menjadi sosok makhluk yang ditakuti. Oleh sebab itu, untuk menghindari gangguannya ada pantangan atau larangan yang harus dilakukan oleh masyarakat setempat. Larangan atau pantangan itu berguna bagi masyarakat bila hendak menelusuri daerah-daerah yang disebut sebagai sarangnya orang bunian agar terhindar dari gangguannya. Adapun laranganlarangan tersebut ditulis secara detail oleh Gus Tf Sakai dalam cerpennya. Berikut kutipan pantangan dan larangan tersebut:

"Semua percaya, jika bertemu orang bunian mereka tak boleh bicara. Tapi akan ada pemburu, teman-temannya dari suku lain, yang

\footnotetext{
${ }^{23}$ Gus TF Sakai, Kaki Yang..., h. 81-82.

${ }^{24}$ Ibrahim Dt. Sanggoeno Diradjo, Tambo Alam Minangkabau: Tatanan Adat Warisan Nenek Moyang Minangkabau, (Bukittinggi: Penerbit Kristal Multimedia, 2013) h. 3-5.
} 
menyertai dengan pantangan. Pantangan yang juga akan tak sama. Ada yang berpantang membawa apa pun peralatan berbuhul rotan, ada yang tak boleh rebahan di antara dua munggu. Ada yang kembali pulang jika melihat binatang dengan tingkah tertentu, ada yang dilarang menggauli istri pada Jumat malam sebelum berburu. Dan ia merasa senang (atau lega?) tak menerima pantangan apa pun dari tetua kaumnya kecuali menjaga apa yang mereka sebut sumangaik". 25

Kemudian, dalam pembahasan ekoligis dari nilai kearifan lokal adalah pengetahuan masyarakat dalam membaca petanda alam. Pada cerpen "Orang Bunian" diceritakan bagaimana masyarakat membaca tanda alam mengenai waktu yang tepat untuk berburu. Berkaitan dengan kearifan lokal adalah tata nilai atau perilaku hidup masyarakat lokal dalam berinteraksi dengan lingkungan tempatnya hidup secara arif, serta menjelaskan bahwa bentukbentuk kearifan lokal yang ada dalam masyarakat dapat berupa nilai, norma, kepercayaan, dan aturan-aturan khusus. Adapun bentuk dari nilai kearifan mengenai membaca petanda alam sebagai waktu yang tepat untuk berburu adalah sebagai konservasi dan pelestarian sumber daya alam dan pengembangan kebudayaan dan ilmu pengetahuan. Berikut kutipan teksnya:

"Sebenarnya, hari itu pagi yang cerah. Semua tanda alam yang sangat ia kenali, sejak malam sampai dini hari, menunjukan besok siang bakal cemerlang. Malam dingin, udara seperti parutan es, dan bumi bagai merembeskan air dari pori-pori tanah. Ia tahu, itulah saat di mana babi-babi lekap lama, menyuruk dalam ke kehangatan sarang, dan buru-buru keluar waktu menjelang. Waktu yang pendek, jangka yang seketika, saat kabut terangkat dan embun dilibas matahari tiba-tiba, babi-babi masih akan berada di perlintasan. Itulah saat yang tepat. Mereka menyebutnya bakutiko: babi-babi masih berkeliaran saat mereka pas tiba di hutan". 26

Cerpen "Orang Bunian" menghadirkan mitos urang bunian dalam penceritaan seakan memberikan pesan tersirat dalam menjaga ekosistem alam. Dalam ceritanya, si ayah menyampaikan bahwa masyarakat di daerahnya selalu melakukan ritual tertentu sebelum berburu babi. Selain itu, untuk menentukan waktu yang baik dan tepat untuk berburu mereka selalu membaca tanda-tanda yang diberikan oleh alam, seperti melihat cuaca dengan merasakan temperatur suhu alam, hingga tidak melanggar semua pantangan. Tanda melihat cuaca dengan merasakan temperatur alam di dalam teks dituliskan sebagai berikut:

${ }^{25}$ Gus TF Sakai, Kaki Yang Terhormat, (Jakarta: Gramedia Pustaka Utama, 2012) h. 84.

26 Gus TF Sakai, Kaki Yang...., h. 84-85. 
"Malam dingin, udara seperti parutan es, dan bumi bagai merembeskan air dari pori-pori tanah. Ia tahu, itulah saat di mana babi-babi lekap lama, menyuruk dalam ke kehangatan sarang, dan buru-buru keluar waktu menjelang".

Diksi "udara seperti parutan es" yang dituliskan dalam teks merupakan bentuk tradisional masyarakat Minangkabau kabau yang digambarkan di dalam cerpen dalam merasakan temperatur suhu alam. "Udara seperti parutan es" dapat dimaknai bahwa kondisi suhu pada saat itu sangatlah dingin. Kondisi suhu pada saat itulah dipercayai oleh masyarakat waktu yang tepat dalam berburu babi. Selain itu, masyarakat juga harus menghindari pantanganpantangan dalam berburu babi. Adapun pantangan-pantangan yang harus dihindari berupa menggunakan perlatan berburu yang berbuhul rotan hingga larangan menggauli istri pada Jumat malam sebelum berburu. Berikut kutipan teksnya:

“...Tapi akan ada pemburu, teman-temannya dari suku lain, yang menyertai dengan pantangan. Pantangan yang juga akan tak sama. Ada yang berpantangan membawa apa pun peralatan berbuhul rotan, ada yang tak boleh rebahan di antara dua munggu. Ada yang kembali pulang jika melihat binatang dengan tingkah tertentu, ada yang dilarang menggauli istri pada Jumat malam sebelum berburu....28.

Pantangan-pantangan tersebut mereka percayai dan mereka amalkan. Hal itu mereka lakukan agar ketika berburu babi ke hutan tidak mendapat gangguan dan musibah. Mereka percaya bahwa hutan juga merupakan tempat hidup makhluk selain manusia, baik itu hewan, tumbuhan dan mahkluk halus jihin (bahasa Minangkabau dalam menyebut jin). Oleh sebab itu, cerpen 'Orang Bunian” dapat dikatakan sebagai cerpen yang mengangkat bentuk-bentuk kearifan lokal suatu kelompok masyarakat dalam menjaga alam dan lingkungannya. Kegiatan berburu babi yang dilakukan oleh suatu kelompok masyarakat di dalam cerpen yang diceritakan oleh Gus TF Sakai sarat akan makna filosofi dalam menjaga ekosistem dan lingkungan.

\section{Penutup}

Dengan membaca cerpen "Orang Bunian" dapat diambil pemahaman mengenai kearifan lokal masyarakat dalam memperlakukan alamnya. Alam dan lingkungan merupakan tempat untuk beraktualisasi, bereksistensi, dan

${ }^{27}$ Gus TF Sakai, Kaki Yang Terhormat, (Jakarta: Gramedia Pustaka Utama, 2012) h. 85.

${ }^{28}$ Gus TF Sakai, Kaki Yang...., h.84. 
berinteraksi bagi manusia. Hubungan antara sesama manusia dengan makhluk lain bisa dijalankan dengan baik, apabila terjadi simbiosis mutualisme, dengan prinsip kerjasama yang saling menguntungkan. Masing-masing saling memberi ruang dan kemerdekaan hidup, sehingga terjalin keselarasan dan keserasian. Seperti yang telah disampaikan sebelumnya bahwa dalam pembahasan ekologis dalam karya sastra juga dapat mempertimbangkan bentuk-bentuk kearifan lokal. Kearifan lokal merupakan semua bentuk pengetahuan, keyakinan, pemahaman atau wawasan serta adat kebiasaan atau etika yang menuntun perilaku manusia dalam kehidupan di dalam komunitas ekologis.

Bentuk-bentuk kearifan lokal yang ada dalam masyarakat dapat berupa nilai, norma, kepercayaan, dan aturan-aturan khusus. Bentuk yang bermacammacam itu mengakibatkan fungsi kearifan lokal menjadi banyak pula. Adapun fungsi kearifan lokal dalam cerpen "Orang Bunian" adalah sebagai konservasi dan pelestarian sumber daya alam, sebagai pengembangan kebudayaan dan ilmu pengetahuan; dan sebagai petuah, kepercayaan, sastra, dan pantangan. Maka dalam hal ini, cerpen "Orang Bunian" mengungkapkan untuk saliang manjago (saling menjaga) dengan tujuan untuk melindungi diri berserta lingkungan sekitar agar tidak berbuat yang senonoh dan merusak lingkungan sekitar.

\section{Daftar Pustaka}

Badan Pengembangan Bahasa dan Perbukuan. Kamus Besar Bahasa Indonesia (Online). Tersedia di https://kbbi.kemdikbud.go.id/entri/jin. Diakses pada 25 Februari 2020 pada pukul 09:34 WIB. 2020.

Chandra, Afry Adi. "Ekokritik dalam Cerpen Indonesia Mutakhir". Jurnal Pena Indonesia (JPI) Vol. 3 No. 2. Hlm. 100-129. 2017.

Endraswara, Suwardi. Metodologi Penelitian Ekologi Sastra: Konsep Langkah, dan Penerapan. Yogyakarta: CAPS. 2016.

Endraswara, Suwardi. Ekokritik Sastra. Yogyakarta: Morfalingua. 2016.

Ibrahim. Tambo Alam Minangkabau: Tatanan Adat Warisan Nenek Moyang Orang Minang. Bukittinggi: Penerbit Kristal Multimedia. 2013.

Karami, Habibullah, Wahyudi Rahmat, Aruna Laila. "Masyarakat Minangkabau dalam Kumpulan Cerpen Kaki Yang Terhormat Karya Gus Tf Sakai". Jurnal Bahasa Vol. 1 No. 2. Hlm. 120-135. 2019.

Moleong, Lexy J. Metodologi Penelitian Kualitatif. Bandung: Remaja Rosdakarya. 2014.

Sakai, Gus TF. Kaki Yang Terhormat. Jakarta: Gramedia Pustaka Utama. 2012.

Sangidu. Penelitian Sastra: Pendekatan, Teori, Metode, Teknik, dan Kiat. 
Yogyakarta: Unit Penerbit Sastra Asia Barat Fakultas Ilmu Budaya Universitas Gadjah Mada. 2004.

Sari, Mardiana. "Ekologi Sastra Pada Puisi Dalam Novel Bapangku Bapunkku Karya Pago Hardian”. Dalam Jurnal Parataksis, Vol. 1 No. 1. Hlm. 1-15. 2018.

Sudikan, Setya Yuwana. Ekologi Sastra. Lamongan: CV. Pustaka Ilalang Group. 2016.

Pemerintah Indonesia. Undang-Undang Republik Indonesia Nomor 32 Tahun 2009 Tentang Perlindungan dan Pengelolaan Lingkungan Hidup. Diunduh pada laman Kementerian Koordinator Pembangunan Manusia dan Kebudayaan. 2009.

Usman, Miftahul. "Pergeseran Nilai Budaya Minangkabau dalam Kumpulan Cerpen Kaki Yang Terhormat karya Gus Tf Sakai," Skripsi Jurusan Sastra Indonesia Fakultas Ilmu Budaya Universitas Andalas. Padang. 2019.

Wasana. Mitos dan Legenda Minangkabau di Kenagarian Abai Kecamatan Sangir Batang Hari Kabupaten Solok Selatan. Laporan Penelitian Dosen Fakultas Ilmu Budaya Universitas Andalas. 2017.

Widianti, Ande Wina. "Kajian Ekologi Sastra" dalam Kumpulan Cerpen Pilihan Kompas 2014. 